\title{
Red meat causing delayed anaphylactic airway edema: a case report
}

\author{
Aparna Das ${ }^{1}$, Saranya Thangavel ${ }^{2}$, Sauradeep Das ${ }^{2}$, Sunil Kumar Saxena ${ }^{2}$
}

\author{
${ }^{1}$ Department of ENT, All India Institute of Medical Sciences, Jodhpur, India \\ ${ }^{2}$ Department of ENT, Jawaharlal Institute of Postgraduate Medical education and Research, Pondicherry, India
}

Received: 11 April 2021
Accepted: 17 May 2021

*Correspondence:

Dr. Saranya Thangavel,

E-mail: softsaran.nrp@gmail.com

Copyright: $\odot$ the author(s), publisher and licensee Medip Academy. This is an open-access article distributed under the terms of the Creative Commons Attribution Non-Commercial License, which permits unrestricted non-commercial use, distribution, and reproduction in any medium, provided the original work is properly cited.

\begin{abstract}
The goals of emergency management of angioedema include prevention of spontaneous eruption, maintaining and securing the airway and to stop the progression of the disease. Laryngeal edema is one of the life-threatening complications of angioedema that can be managed by endotracheal intubation or emergency tracheostomy or cricothyrotomy. Recently, delayed onset food induced anaphylactic reactions are being recognised widely due to better clinical knowledge and technology that can substantiate the diagnosis. The classical finding of anaphylaxis to only proteins have been disproved and delayed onset food allergy (i.e.) 3-6 hours after ingestion of food has been attributed to specific carbohydrate moieties in glycolipids and glycoproteins such as Galactose- $\alpha-1,3$-galactose found in red meat (beef, pork and lamb). Even though it is seen rarely in the Indian population, it should be a part of the diagnostic algorithm in order to prevent fatal complications. Hereby reporting 39 years old male with undiagnosed red meat allergy presented with features of foreign body sensation throat and laryngeal oedema and managed conservatively with steroids and nebulisation.
\end{abstract}

Keywords: Angioedema, $\alpha$-gal, Red meat, Dysphagia, Anaphylaxis

\section{INTRODUCTION}

Anaphylaxis can be of two types, immediate onset and delayed onset. Anaphylaxis is defined as an immediate onset IgE antibody mediated type I hypersensitivity reaction that occurs within 5-30 minutes after ingestion or injection of the allergic agent. ${ }^{1}$ Food and venom has been found to be the most common causes of anaphylactic reaction in humans by various studies. ${ }^{2,3}$ Anaphylaxis presents with characteristic gastrointestinal, respiratory and skin reactions. Angioedema, pruritis of oral cavity and throat, nausea, vomiting, abdominal pain, diarrhoea and melena can be the gastrointestinal symptoms. Urticaria, pruritis and erythematous rash are the cutaneous symptoms. Cough, dyspnoea, stridor and wheezing can occur due to upper airway edema and lower respiratory tract involvement. ${ }^{4}$ Delayed onset anaphylaxis is a rare event and here we present a rare case of delayed onset anaphylaxis with upper airway edema following ingestion of beef (red meat).

\section{CASE REPORT}

A 39-years-old male with no known co-morbidities presented to us with history of difficulty in swallowing and voice change within four hours of beef meal ingestion which he tried for the first time. There was no history of choking, cough, breathing difficulty, fever or vomiting. There was no history of similar episodes in the past.

On clinical examination, the patient was comfortable at rest and no stridor. On auscultation, bilateral air entry was equal. Oral cavity and oropharyngeal examination were normal and indirect laryngoscopy revealed an overhanging mildly oedematous epiglottis with pooling of saliva in bilateral pyriform sinus and mild edema of arytenoids and adequate glottic chink with no airway compromise. The Xray of soft tissue neck lateral view revealed edematous epiglottis with edematous upper airway mimicking foreign body oesophagus (beef bolus) (Figure 1). Patient was diagnosed as a foreign body in oesophagus and planned for 
rigid esophagoscopy and foreign body removal under general anaesthesia.

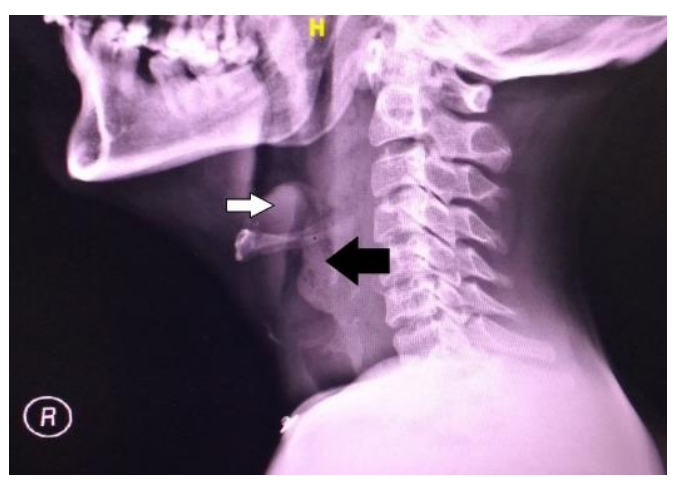

Figure 1: X-ray soft tissue neck lateral view showing thumb shaped edematous epiglottis (white arrow) and edematous upper airway mimicking foreign body oesophagus (beef bolus) (black arrow).

As the patient was taken up for surgery, his change in voice worsened and he developed mild breathing difficulty. Hence, immediate intubation with tracheostomy as backup was decided. On table, video laryngoscopy by anaesthetists showed edematous epiglottis, aryepiglottic fold and arytenoids. With difficulty, the patient was intubated with 7 size endotracheal tube.

Rigid esophagoscopy under general anaesthesia was done but no foreign body was found till gastro oesophageal junction. Minimal mucosal injury was noted in the posterior wall of upper esophagus just below cricopharynx. Patient was nebulized with adrenaline and successfully extubated. Immediate post-operative period was uneventful and clinical examination revealed edematous uvula with anterior pillar congestion. Patient was started on injection dexamethasone eighth hourly along with intravenous antibiotics post operatively. Patient improved symptomatically within two days postoperatively and regained his voice and ability to swallow.

Video laryngoscopy done three days after the procedure revealed normal epiglottis, arytenoid, and aryepiglottic fold with normal mobility of bilateral vocal cord with no pooling in bilateral pyriform sinus and X-ray soft tissue neck revealed normal supraglottic airway with normal epiglottis and arytenoids. Patient was discharged on oral antibiotics on post-operative day 3 .

\section{DISCUSSION}

We have reported a case of delayed onset anaphylactic reaction after ingestion of beef (red meat). The patient presented with dysphagia and mild edema of arytenoids which clinically suggested a foreign body oesophagus which was substantiated by an X-ray. The patient was uneventfully intubated and extubated after a rigid esophagoscopy which was negative for a foreign body oesophagus.
Following extubation, the edema progressed rapidly on to the aryepiglottic folds, epiglottis, tonsillar pillars and the uvula. Patient had developed mild breathing difficulty prior to the procedure and post operatively patient was managed conservatively with $8^{\text {th }}$ hourly intravenous dexamethasone and $6^{\text {th }}$ hourly adrenaline nebulisation. Patient did not show any cutaneous or gastrointestinal manifestations. The patient improved drastically.

Mapping of IgE binding epitopes on food allergens has been successfully achieved over the years due to technological advancements. ${ }^{5}$ Most epitopes identified are proteins. Recent studies have shown that $\mathrm{IgE}$ antibodies can target certain carbohydrate moieties.

The $\alpha$-gal syndrome is a newly evolving syndrome in which IgE antibodies target Galactose- $\alpha-1$, 3-galactose, an oligosaccharide, present in glycolipids and glycoproteins in red meat (beef, pork and lamb). $\alpha$-gal is presented to antigen presenting cells long after the ingestion of red meat due to delayed absorption of lipid and protein complexes in the gastrointestinal tract accounting for the 3-6 hours delay in anaphylaxis. ${ }^{6,7}$

The affected patients should not only avoid red meat but also $\alpha$-gal containing drugs such as Cetuximab or vaccines or gelatin containing colloidal solutions. ${ }^{8}$ Some recent studies have associated tick bites to type I sensitisation and allergy to $\alpha$-gal. ${ }^{9}$

The patient did not have any underlying history of atopy and studies have shown that $20 \%$ of patients with food allergy usually have asthma or hay fever. ${ }^{10}$ Since the agent causing anaphylaxis was food, it was easily identified and avoided, unlike certain conditions like allergic rhinitis where the causative agent is difficult to find and requires an array of sensitisation tests. Our patient was advised to avoid red meat from his diet to prevent any further anaphylactic reactions in the future and patient was discharged on post-operative day 3.

\section{CONCLUSION}

Recent studies have proven that red meat (beef, pork, lamb) can cause delayed onset anaphylaxis due to its carbohydrate moieties unlike the classical teaching of anaphylactic reactions to protein components. Even though delayed onset anaphylactic reactions are a rare event, it should always be a differential diagnosis because an early intervention can prevent morbidity and mortality.

\section{Funding: No funding sources \\ Conflict of interest: None declared \\ Ethical approval: Not required}

\section{REFERENCES}

1. May CD. Objective clinical and laboratory studies of immediate hypersensitivity reactions to foods in 
asthmatic children. J Allergy Clin Immunol. 1976;58:500-15.

2. Yocum MW, Khan DA. Assessment of patients who have experienced anaphylaxis: a 3-year survey. Mayo Clin Proc. 1994;69(1):16-23.

3. Kemp SF, Lockey RF, Wolf BL, Lieberman P. Anaphylaxis. A review of 266 cases. Arch Intern Med. 1995;155(16):1749-54.

4. Sampson H. Food allergy-accurately identifying clinical reactivity. Allergy. 2005;60:19-24.

5. Sampson HA. Update on food allergy. J Allergy Clin Immunol. 2004; 113:805-19.

6. Commins SP, Platts MTA. Allergenicity of carbohydrates and their role in anaphylactic events. Curr Allergy Asthma Rep. 2010;10:29-33.

7. Commins SP, Satinover SM, Hosen J, Mozena J, Borish L, Lewis BD, et al. Delayed anaphylaxis, angioedema, or urticaria after consumption of red meat in patients with $\mathrm{IgE}$ antibodies specific for galactose- $\alpha-1$, 3-galactose. J Allergy Clin Immunol. 2009;123:426-33.
8. Fischer J, Biedermann T. Delayed immediate-type hypersensitivity to red meat and innards: current insights into a novel disease entity. JDDG J Dtsch Dermatol Ges. 2016;14:38-43.

9. Commins SP, James HR, Kelly LA, Pochan SL, Workman LJ, Perzanowski MS, et al. The relevance of tick bites to the production of $\operatorname{IgE}$ antibodies to the mammalian oligosaccharide galactose- $\alpha-1$, 3galactose. J Allergy Clin Immunol. 2011;127:128693.

10. Cooke RA, Vander Veer A. Human sensitization. J Immunol. 1916;1:201-305.

Cite this article as: Das A, Thangavel S, Das S, Saxena SK. Red meat causing delayed anaphylactic airway edema: a case report. Int J Otorhinolaryngol Head Neck Surg 2021;7:1059-61. 